\title{
$\underline{\text { Resident Perceptions of an Overt Drug Elimination Strategy }}$
}

By: M. Kristen Hefner, James M. Frabutt, Lynn K. Harvey, Kristen L. Di Luca, Terri L. Shelton

Hefner, M.K., Frabutt, J.M., Harvey, L.K., Di Luca, K.L., Shelton, T.L.(2013). Resident Perceptions of an Overt Drug Elimination Strategy. Journal of Applied Social Science, 7(1), 6179. doi: $10.1177 / 1936724412462339$

Made available courtesy of Sage Publications: http://dx.doi.org/10.1177/1936724412462339

***(C) The Authors. Reprinted with permission. No further reproduction is authorized without written permission from the authors \& Sage Publications. This version of the document is not the version of record. Figures and/or pictures may be missing from this format of the document. $* * *$

\section{Abstract:}

Open-air drug markets are destructive to communities and negatively influence community residents. To combat open-air drug markets, a data-driven, focused deterrence approach drawn from David Kennedy's "pulling levers" framework was used in two North Carolina cities. Until now, the elements of the strategy have only been articulated through the perspective of lawenforcement personnel. However, community residents living in open-air drug market areas offer critical perspectives that frequently go unvoiced. Through the use of focus groups with community residents, this article elucidates the perspectives and perceptions of community residents as they relate to the strategy and emphasizes the imperative community role in deterring drug crime.

Keywords: community residents | open-air drug market | law enforcement

\section{Article:}

Open-air drug markets are exceptionally destructive to the communities of which they are a part and negatively influence the ways community members interact, communicate, and behave. In addition, the quality of life of the community residents who live in areas with thriving overt drug markets is often negatively affected by their existence. Harcopos and Hough (2005), drawing on numerous scholars (Hough and Edmunds 1999; Knutsson 1997; Weisburd and Mazerolle 2000; Wilson and Kelling 1982), noted that open-air drug markets promote a variety of social disorder and crime that often lead to reduced feelings of public safety by community residents.

Moreover, the safety and security of community members who reside in neighborhoods wrought by overt drug dealing are compromised, and residents are often faced with complex predicaments that are intertwined in relationships with other community members, drug dealers, and lawenforcement officials. These intertwined relationships are characterized by particular norms and narratives - the often misguided and unchallenged beliefs that groups of people possess 
regarding the behaviors and motivations of other groups - that influence how individuals behave and the social responses associated with those behaviors (Kennedy 2009). According to Frabutt et al. (2006), community residents are involved in relationships with both drug dealers and lawenforcement officials who are simultaneously valued, needed, and abhorred. But the underlying norms and narratives that guide these relationships are rarely elucidated or challenged.

Research shows that traditional deterrence measures that generally consist of imposing punishments in a way that they are certain, swift, and severe may be ineffective in preventing criminal and illegitimate behaviors, including open-air drug dealing, for various reasons (Kennedy 1998). The majority of crimes go unreported or are unknown to police. Moreover, most of the crimes that are reported do not end in arrest and therefore, a sentence is not imposed. For the punishments that are imposed, they generally are not certain, not put into effect swiftly, and the perceptions of the severity of the punishments vary from individual to individual. In addition, the more traditional model of deterring criminal behavior does not take into account the contexts in which and the motivations why criminal behaviors occur. Furthermore, "while research has repeatedly suggested that the certainty and swiftness of sanctions matter more than their severity, most of the political and policy debate has centered on increasing sanctions” (Kennedy 1998:4).

In an effort to combat overt drug markets and the associated violence that afflicts the overall well-being of the neighborhood and the community residents who reside in these locations, a data-driven, focused deterrence approach has been implemented in two communities in North Carolina. This specific approach is drawn from Kennedy’s (1998) “pulling levers” framework, which takes into account new conceptual ways of thinking about policing and ways of coming to resolutions across organizational boundaries while, at the same time, circumventing the limitations of more traditional deterrence methods. By recognizing the structural nature of violence, this approach originates from the understanding that law enforcement cannot exclusively fight the social and criminological challenges that often accompany many urban crimes (Curtis and Wendel 2007).

The pulling levers framework consists of various elements (Braga 2008). First, a specific social and criminological problem is identified within a particular community, such as open-air drug markets or gun violence perpetrated by youth or gang members (Braga et al. 2008). After the behavior or problem is identified, law-enforcement officials conduct extensive research and undercover investigations to identify the small number of individuals and/or groups who drive the problem. Subsequently, a community response, known as a "call-in” or "notification," involving various partners, including law enforcement, community stakeholders, community residents, and family members of the individuals identified, is constructed that uses a variety of legal "levers" (or actions) that can be "pulled" (or activated) if the behaviors do not cease (Braga 2008). Although the legal levers are used to illustrate the seriousness of the strategy and of the stakeholders involved, other levers also exist. Neighborhood residents make the unambiguous statement that illicit and violent behaviors will no longer be accepted as a part of their 
community. In addition, as a part of the response, community resources are coordinated with the legal efforts to provide support to the criminal actors, such as financial, educational, and psychological assistance. So, although the message from both law-enforcement officials and community members that violence will no longer be tolerated within the community is unyielding, supports are also available to aid the offenders in the transition to a less destructive lifestyle. It is important to note that although the previously outlined structure of the model is a general framework, slight variations do exist across communities. However, the main elements of the strategy are consistent among sites. Therefore, the specifics of each city's implementation are not elucidated within this article.

Thus, the focused deterrence model combines methodical data collection and police-community partnerships to identify, caution, assist, and if needed, reprimand drug offenders who are causing a great deal of harm to the communities in which they sell drugs. More specifically, this strategy controls violent behavior by focusing on a small group of chronic offenders who are committing a majority of the criminal behavior in an area and deters crime by addressing both the individual behavior and the collective, societal norms that influence it.

Thus far, various elements and phases of the overt drug elimination strategy based on Kennedy's focused deterrence model have been expressed only from the perspective of law-enforcement partners (Frabutt et al. 2010) and key stakeholders (Frabutt, Hefner, et al. 2009). However, the community residents who live each day in the neighborhoods in which the strategies are implemented provide essential perspectives that are often unknown to law-enforcement personnel and community stakeholders. Through the use of focus groups, this article presents community residents' perceptions of various elements and dynamics of their community before and after the overt drug elimination strategy was implemented, including their perceptions of elements of the strategy, crime, personal safety, the police, and community member involvement. Specifically, in evaluating the participants' responses, several central elements were elucidated, including illustrations of the community's norms and narratives, the continued need for youth support and engagement, discussions centered on the impacts of the strategy, and issues around strategy maintenance and the need for increased police visibility. Thus, this article illustrates the importance of community engagement in strategic law-enforcement initiatives.

\section{Method}

\section{Participants}

Three focus groups were held in two cities where the overt drug elimination strategy was implemented in North Carolina. ${ }^{1}$ The focus groups were convened by key residents and housing authority employees in the initiative areas, and were facilitated by members of the research team. Collectively, 22 community residents participated in the sessions. In one city, 8 community residents attended the first focus group and 3 the second. In the other city, 11 community residents from the initiative area participated. ${ }^{2}$ Participants had resided in the initiative area for 
varying amounts of time, ranging from 4 to 38 years. Most of the residents in attendance were African American.

Convenience sampling was used in obtaining the focus group participants. The participants were recruited by a member of the cities' housing authority and by a local minister in the initiative area. To select the focus group participants, the housing authority members conferred with the Presidents of the Resident Councils who chose an array of active and concerned residents in the community, and the local minister selected participants to invite who were involved with strategy implementation. In extending participant invitations, recruitment efforts were made in attempt to ensure that all segments of the community were represented.

The participants who took part in the focus groups had different levels of understanding regarding the overt drug elimination strategy executed in their neighborhoods. Although we understand that our sample may not be representative of all residents who reside in communities in which the strategy may be implemented, there is no reason to think that the subsequently articulated themes would necessarily be limited to these groups (Weiss 1994). In addition, on the whole, the findings do not differentiate between the residents in each implementation area because the themes described provide an overview of some of the possible community perspectives that should be taken into account in implementing a strategy of this type. Thus, the themes presented provide interesting and useful ideas for the implementation of strategies that combine both law enforcement and community resources.

\section{Materials and Procedure}

The research team developed a group interview format design to delineate the focus groups' direction and to ensure that the appropriate responses were elicited from the participants. The general focus group discussion guide is available in Appendix B. Prior to commencing the focus group sessions, participants provided their informed consent as well as the number of years of residency in the neighborhood.

The focus groups were held at a community center or church located within the initiative neighborhoods, which served as a convenient location for the community residents. The focus groups lasted between 50 and 80 minutes. A member of the research team served as the moderator, introduced the remaining research team members in attendance, and described to the participants what the focus group would entail. At the end of each session, the moderator thanked the participants for their contributions. Subsequently, each participant received a \$35 gift card as compensation for his or her time and contribution.

With the participants' consent, the focus groups were audio recorded. Three separate digital recorders were used to capture all participants' contributions. The verbatim recordings of the sessions were stored electronically in a secure format and were reviewed by members of the research team. Following the interviews, the audio recordings were compiled into transcriptions for subsequent analysis. 
To code the focus group transcriptions, the interview protocol was divided into three main themes: strategy knowledge and awareness, direct strategy involvement, and resident perceptions of crime, personal safety, the police, and the community in general. These three major thematic areas created predetermined coding categories, which corresponded to the researcher-initiated questions during the focus groups. As a method to distill the data, a matrix was created that cross-tabbed the major thematic foci of the interview with the individual focus group sessions. This streamlined representation of the data allowed simultaneously for cross-site comparison and within-site analysis. Members of the research team analyzed the focus group transcriptions for responses corresponding to each predetermined theme separately and then convened to compare the coded data. The coding process was iterative, featured multiple immersions in the original transcripts, and was collaboratively informed by members of the research team.

\section{Findings}

The focus groups took place between two and four years following the notifications in the initiative areas. Regardless of the fact that a relatively long period of time took place between the implementation of the strategy and the focus groups, the participants recalled a good deal of information regarding the overall strategy. Analysis of the resident perspectives gleaned from the focus groups is presented according to the three major emergent categories: strategy knowledge/awareness, direct strategy involvement, and resident perceptions of crime, personal safety, the police, and the community. To ensure the anonymity and confidentiality of the research areas and participants, the following findings are presented in a generalized format and are not differentiated by the specific communities used in the study.

\section{Strategy Knowledge/Awareness}

As stated previously, the focus group participants had varied levels of awareness about the overt drug elimination strategy implemented by the police department. However, across all three sites, 17 of the 22 participants expressed that the strategy was not explained to them by the police department or other community agency. Only one focus group participant reported that he or she attended the community meeting where the police department presented the strategy to community partners. In one site, all 11 participants recalled being informed by their particular police department about the notification strategy prior to the event at a community awareness meeting. Furthermore, three of these participants also had been made aware of the strategy through media coverage and direct conversations with their respective police departments.

In one site, a recent "sting” effort was conducted by the police department in an effort to continue the maintenance phase of the strategy in that particular community. All eight participants in the community had knowledge of the sting operation that occurred and provided various descriptions of the event ranging from reasonably accurate to exaggerated descriptions. The participants' overall understanding of the sting was that the police department conducted surveillance on people in the neighborhood and arrested the individuals who were engaging in 
illegal activities. Regarding the arrests made during the sting operation, most participants had accurate information on the number of people arrested. Some had seen a community newspaper, which included a list of who had been arrested based on the police department's strategy. Of those who had seen the newspaper, the consensus was that the document was not distributed throughout the community in which the strategy was implemented. The community residents expressed that this information needs to be provided to every community resident for them to help keep their community safe.

While some of the participants' understandings of the sting operation were accurate, others were exaggerated. Some participants stated that they heard helicopters over the neighborhood and saw the police jumping out of them. Others saw police cars crowd the area. One participant mentioned that she heard the police had administered DNA testing on offenders in the neighborhood. However, although some of the perceptions of what occurred during the sting were sensationalized, the participants' overall knowledge of the sting operation that occurred in the initiative area was fairly accurate.

In one session in particular, all 11 participants also expressed agreement that their neighborhood had been selected for the initiative because of the high crime rate and drug market activity. Although about half of the 11 participants were clearly able to explain the messages being delivered at the call-in session, only one participant attended the session.

The participants also were asked about their knowledge of the notification or call-in that occurred several years beforehand, during the first phase of the initiative. Approximately, 13 of the total participants (just over half) were aware of the notification taking place: 4 or 5 of the 11 participants in the first focus group session, all 8 in the second, and 2 of 3 in the third. According to the participants who were aware of notification, the purpose of the session was to redirect the thinking of the offenders in the community and to show that other options exist besides drug dealing. The attitude also was expressed that the police were trying to assist the young offenders in the neighborhood to prevent them from acquiring a criminal record due to the difficulties that subsequently creates for finding future employment and obtaining future resources. The community residents stated that training and school opportunities were offered to the offenders, but felt like what the dealers really needed was financial assistance. One participant stated,

What I've heard from these boys ... and girls that were watched was that they really needed financial [help] because if you go to these trainings, money's not coming in and that's why they turned around and did it [drug dealing] back again.

Overall, community residents in all three initiative areas were knowledgeable about activities, legal and illegal, that occur within their community, including crime and drug dealing. Not only were the residents aware that crime and drug dealing occur in their neighborhood but they were also cognizant of offender patterns, modifications in behaviors, and various ways in which offenders attempt to deceive the authorities. 


\section{Direct Strategy Involvement}

The focus group participants were asked about their involvement in their respective strategies. Of the 22 participants, 5 had attended the notification sessions. Two of the focus group participants, who were very involved in the overall community, attended the call-in and spoke to the offenders on behalf of the community. These community residents also attended meetings with the local police department and were strong advocates for their efforts. No other participants had any direct involvement in the overt drug elimination strategy. The focus group participants expressed the opinion that the community residents need to become more engaged by reporting crimes and illegal activities to the police to help deter crime in their neighborhood.

\section{Resident Perceptions of Crime, Personal Safety, the Police, and the Community}

The focus group participants were asked about their perceptions of crime in the neighborhood, personal safety, the police, and their community in general both before and after the strategy was implemented. In terms of criminal activity in the neighborhood, all 22 participants stated that drug dealing had decreased in their neighborhoods since the police department conducted the sting operation and/or the notification, but that dealing is still present, and offenders continue to come back into the neighborhood to sell drugs. One community resident stated,

Right after, we saw a change. It's just like with the sting. We've seen a change, but they're gradually coming back. And that's the way it was last time [during Phase 1], you know, they [the police] back down, but gradually . . . you know, they're [dealers] moving back in.

The decrease in, but continuing presence of, drug dealing in the neighborhoods expressed by the residents is consistent with police data from the areas. Specifically, longitudinal data not only show a substantial and sustained decrease in drug dealing and associated criminal activities over several years after the intervention was implemented but also illustrate that the dealing was not completely eradicated by the strategy (Frabutt, Shelton, et al. 2009).

One participant expressed the impact of the message in terms of community awareness: "They [the dealers] know not to come back here because the people are not going to take it." Moreover, many participants asserted that most of the decreases in dealing had occurred during daytime hours, but dealing was still fairly heavy in the evenings and at night.

The community residents attributed part of the decrease in drug dealing to increased police visibility and heightened scrutiny of the neighborhood. However, about half of the eight participants in one community noted that various physical obstacles were present in the neighborhood that can obstruct police surveillance of the area. The residents noted that areas exist where the dealers can hide the dealing or the drugs from the police, such as behind bushes and certain buildings. The participants also attributed part of the decrease in drug dealing to the willingness of community members to report crimes to the police. 
The community residents were, overall, very knowledgeable about the temporal patterns of the drug dealers. Many of the 22 residents stated that the dealers work in shifts throughout the day. The most drug traffic occurs from five o'clock in the evening until the morning. The participants also asserted that drug dealing varies with citywide pay schedules, becoming most intense during times of the month when employees are paid. In fact, some of the participants in one session noted having observed city employees coming through the neighborhood to buy drugs during those times.

The focus group participants also were asked about their perceptions of personal safety before and after the strategy was implemented. Overall, a large majority of the 22 participants felt the community was much safer after the strategy was implemented than before. The residents were no longer afraid to walk around their neighborhood. One participant stated,

Well, I want to say it uh, it's much safer now than it had been, and I'm not afraid to walk around any community at no time, because I know I have protection around me and I'm not afraid to walk around in the community and it's much, much safer now than it has been.

Three residents spoke about how children are now out playing in the parks and on the sidewalks. One resident of 13 years expressed that the difference from when he moved to the initiative area to now is "like night and day." The resident explained,

Afterwards you could see kids going to the store by their self. You still see them today. Before that you, parents wouldn't let their kids and you couldn't blame them, because there were drug dealers out on the street, but it made a big difference, in the daytime and night.

However, according to all 11 participants in two initiative areas, the feeling of safety started to diminish between two and four months after the notification took place. Even with the decreased sense of personal safety after the notification, the community continued to feel safer than before the strategy was implemented. According to one focus group participant,

I work in the community and I usually, you know, now I can walk now no problems at all, but you know, back months ago I used to have a few little problems, you know, but I just keep on walking. And now, since our management and the police department and stuff came in and got some of the [inaudible] out, it's easy to walk now. No problems.

But even with an overall increased sense of personal safety since before the strategy began, several security problems were still present in the neighborhood. One participant spoke about not being able to sit on her porch in the evening, because the porch is shared with other apartments and the young people take over. Another community resident mentioned that the back of the apartments look identical to one another and therefore, if a dealer was trying to hurry inside for 
any reason, one apartment could be mistaken for another. In reference to that issue, one participant stated,

All these apartments looking alike, especially from the back. If there's drug traffic coming in to someone's house, your houses can be easily mistaken for someone else, and if you don't have a lock on your screen door they will open it up and come on in. And to me that's a great concern.

About half of the eight participants in one initiative area also reported that individuals who are nonresidents of the community come into the area during the late night and early morning mainly to sell drugs, because this is where the drug market is located. Many young mothers allow dealers from other parts of the city to stay in and sell drugs out of their homes. This is a convenient adaptation for the dealers because the police department is monitoring dealing on the streets. According to the focus group participants, the young women think the dealers will help them by paying for bills and helping with the children. However, the dealers come and go whenever they need money, a place to stay, or to sell drugs.

In addition to criminal activity and personal safety, the focus group participants were asked about their perceptions of the police before and after the implementation of the strategy. In contrast to their relatively uniform perceptions about crime and personal safety, participants expressed mixed perceptions about the police. One participant felt that the police had been excellent all along, whereas another was very vocal about his frustration with the police department and for several years felt like he tried everything he could to get them to take any action in the neighborhood, even approaching City Hall and the mayor directly. One resident expressed a concern about turnover in the police department, specifically with the hire of the new Chief. He spoke about how he was concerned that with a new Chief they would lose the commitments that the previous Chief had made to change the community and recalled giving the new Chief a pretty hard time at the onset. In short time, his concerns were dispelled and he referred to the new Chief as "the best thing that has happened to [city].” He continued,

[The Police Chief] and the police department put us on our feet; it's up to us to take steps to where we want to go. They can't be right behind us holding our hand every time. Of course, you know, if you call or something like that, that's true. But every time something happens we got to stand on our own two feet. As a community, we can do it. You can't, you can't uh, expect every time we have a meeting that the, uh, Chief of police or somebody higher up is going to be there. They started this program. It's up to us to see it through. It's our community.

More than half of the 22 total participants expressed having a closer relationship with the police following the notification resulting from increased police visibility in the community, attendance at community meetings and events, and communication with residents about what is going on in the neighborhood. 
One suggestion by many residents was that the police should be more visible throughout the neighborhood. Over half of the eight focus group participants in one session agreed that the community was safer when the police foot patrol was active in the neighborhood. "It was much, much better when we had our foot patrol, but when they took the foot patrol out of [the neighborhood] it just became an open-air drug market.” Similarly, the same number of participants in the same area mentioned that they would like the officers to get out of their patrol cars while patrolling the area. A great deal of crime occurs hidden from the view of officers in patrol cars, such as behind apartments, bushes, and other buildings. One participant stated,

I feel like if the police would be more, a little more visible, it'd be a little bit more better. They are not umm, visible enough. Because I noticed that when the police is more visible, you know what I'm trying to say, the crime situation goes down. Boys are not hanging around if they know the police is going to be here today and then they don't know whether they're coming back tomorrow, but the hours that they looking for 'em, they don't come, but they show up a little later, they not going to be on the streets selling drugs. But, if they stay, the police stay off two, three days and don't let 'em see 'em, they back on the street.

Overall, the participants believed that some of the police officers do care about the well-being of this particular community, but feel some of the officers may be a bit afraid to get out of their patrol cars because of the fear of being injured in the neighborhood. The participants believed the perceived fear by some of the officers is justified because young offenders have the potential to engage in extreme behaviors, even as far as coming after an officer. According to one community resident,

A lot of 'em, they have families too. And a lot of times what, what people are carrying on them could hurt them. You know and I always tell 'em I know they got families and they got mommas and daddies too. And I tell them to be careful. I tell the police to be careful. You know if you need to come to my house, come in. It's a safe house. You never, cause you never know when they might turn and run down the police.

Nine participants (41 percent) were very vocal about being willing to call the police when they see illegal activities occurring in the neighborhood. Other participants had reservations about calling the police for various reasons. According to this participant,

I work a third shift, and I come in, in the morning, and there are people that are not from our community walking. There's some times I just sit in my car and they'll come up to the car and start banging on my window and you know, and I haven't thought about calling the police, but that's the time of the morning that you know, that there are all kind of people walking up and down the street.

The focus group participants were also asked about their perceptions of the community in general before and after the strategy. Various positive community changes had occurred in the 
neighborhood since the implementation of the strategy, such as residents feeling safe to walk around the community. In addition, six of the eight participants in one area stated that various community members had prepared a variety of prosocial activities for the residents and youth, including summer picnics and youth events at the community center. As one participant stated,

They have a lot of stuff for 'em. They have uh, summer picnics. Uh, [name of community member], you know, she does things with the community, you know. Ain't a lot of good things with the community besides these drugs. Now we got some, some older people in the community and they do good things for the community and for the kids. It ain't all bad you know.

However, although positive changes have occurred in the community, several concerns continued to appear in the minds of the residents. One great concern was for the children in the neighborhood who have a great deal of idle time and who observe the illegal activities taking place. The participants agreed that more activities need to be created, perhaps hosted at the community center, so that the children will not continuously witness drug dealing and crime in the neighborhood. The participants emphasized the negative behaviors and activities that the children in the area observe as illustrated in this short dialogue:

Participant 1: And the children, they know more drug dealers than the police.

Participant 2: Yeah.

Participant 3: They know exactly who’s selling drugs.

Other community concerns included the need for more parental involvement and the need for the young dealers to obtain employment so they will not have as much idle time. As one participant stated,

I think if, if boys, the younger people, the ones that are eligible, our young kids that are eligible to work, back when I was coming up they had jobs [inaudible] summer youth programs. They don't have that anymore, so they have idle minds, you know, they stay at home, they got little sisters and stuff ain’t gonna babysit em. So if I feel that if we, you know, if the community could find jobs for some of these kids that would at least give em something to do.

Although there was consensus among the groups that the communities continued to have qualityof-life concerns, positive perceptions of the community at large since the call-in were also evident. One resident said they are more aware of who is around and in the neighborhood, and another talked about a decrease in criminal behavior and drug sales. Specifically, participants talked about children being out playing and going to the store, and about police officers being visible and working with the community. Although one community was noted by a resident as 
having had the worst reputation in town prior to the call-in, they now feel safer there than in other communities in the city.

\section{Discussion and Conclusion}

In evaluating the focus group participants' responses, several main elements of the overt drug elimination strategy, from the perspective of the community, came to the forefront. The central elements elucidated included illustrations of norms and narratives that exist within the community, the level of knowledge and awareness the residents have about the strategy and the neighborhood in general, the continued need for youth support and engagement, discussions centered on the impacts of the strategy, and issues around strategy maintenance and the need for increased police visibility.

\section{Norms and Narratives}

One fundamental element of the overt drug elimination strategy centers on the particular norms and narratives that are present within a community that directly influence the ways individuals behave. According to Kennedy (2009), although the norms and narratives that exist significantly affect the lives of the people who reside in these neighborhoods, they are very rarely dealt with across community groups, leading to mistaken beliefs between groups and defective means of dealing with community problems. In addition, according to Kennedy, "Powerful narrativesaccounts of and explanations for what is going on-are developed by the affected communities, by law enforcement, and by drug dealers themselves” (2009:142).

First, a racial and ethnic narrative in minority neighborhoods exists as it relates to oppression by law-enforcement officials. Kennedy states, “A dominant community narrative embeds drug issues and the community's experience with drug enforcement in the historic experience of minorities, especially African Americans, in America” (2009:142). Another existing narrative within these communities is the idea that the police are ineffective in combating drug dealing and cause authentic damage to the community. According to Kennedy, "High levels of enforcement, arrest, and incarceration are seen as the intended outcomes of a deliberate outside attack, designed to destabilize the community, control strong young men, and provide work for lawenforcement agencies and prison staff” (2009:143). Therefore, community members often see law enforcement as being part of the problem, as opposed to part of the solution.

Second, a racial and ethnic narrative exists in the minds of law enforcement, in which the community is viewed as being permanently fractured and the community members are perceived as being aloof or ambivalent about their community and tolerant of any criminal behaviors that take place in it. Moreover, this perception holds that everyone in the community is in opposition to law-enforcement authorities. In particular, law-enforcement officials often feel that residents do not take responsibility nor enforce social standards for the young people within their community (Kennedy 2009). In addition, the drug dealers are often seen as being unreasonable and sociopathic (Kennedy 2009). As a result of the previously mentioned narratives that exist 
within law-enforcement agencies, similar to the consequence of the narratives community members possess, law enforcement often perceives the community as being part of the drug problem and not part of the answer.

Third, norms exist among drug dealers that allow groups of offenders and delinquent peers to produce and maintain the ideas that the life choices available to the dealers are limited due to racism in our society, and therefore, they are justified in participating in the drug trade.

Moreover, the narrative exists that

arrest, incarceration, and death are inevitable and nothing to be afraid of, that "respect" is everything and disrespect must be met with violence; that the community tolerates or supports what they do; and that the police and others in law enforcement are racist predators. (Kennedy 2009:143)

According to the design of the overall strategy, the negative norms of a community may shift toward more positive norms as an additional result of the strategy's work, above and beyond the elimination of the overt drug markets and the corresponding violent behavior.

Several of the focus group discussions centered on the traditionally negative norms that have existed and continue to exist within the community. However, evidence suggested that some of the negative norms were shifting to more positive ones within the community. In reference to illustrations of negative norms that continue to exist in the community, some of the descriptions the participants provided of their understanding of the sting operation were exaggerated and most likely based on negative norms that exist within the community about the police and their treatment of crime and criminal offenders. As stated previously, the focus group participants believed that the police flew over the neighborhood in a helicopter and several police officers jumped out of the aircraft into the area. In addition, one participant heard that the police had administered DNA testing on several offenders in the area. The previously mentioned examples portray the police as being obtrusive in their response to criminal behavior and causing undue harm to the community, which speaks directly to the norm of the police working against, instead of on behalf of, low socioeconomic status, minority communities.

During a subsequent discussion, one participant spoke about having drug dealers approach her vehicle when she arrived home from work, but had not considered calling the police. The failure of this participant in contacting law-enforcement officials suggests that drug dealing has become a normative behavior in this particular community and is often viewed as a recurrent behavior that no one can deter, not even law-enforcement officials. The police have attempted to combat the drug problem in the community to no avail. Many community residents in this neighborhood, and other similar neighborhoods, believed that the police cannot prevent or terminate drug dealing, so calling the police when drug dealing is witnessed is ineffective and a waste of time.

Although several examples were presented to illustrate the traditionally negative norms of the community, examples from some residents also illustrated the potential for change in the 
community's norms. One of the focus group participants asserted that community residents should call the police when criminal behavior is witnessed for the individuals who live in the area to play a positive, proactive role in making their neighborhood a safer place to live. The other participants present agreed with this sentiment. This example speaks directly to the changing nature of this community's norms and how the residents' view of the police may be shifting to include a more positive association between law-enforcement officials and the community in which the residents live.

Participants' understandings of the sting operation and the discussion of the community's reluctance to call the police are illustrations of Kennedy's (2009) notions that norms and narratives exist in communities that powerfully and tangibly influence the individual and group behaviors of the residents, offenders, and law-enforcement officials. Moreover, the latter example shows that the negative norms that have existed for so long can be transformed and, in this particular case, may be changing toward a more positive direction. The example shows that the residents do care about their community and are willing to stand up for the safety and health of their neighborhood if presented with the right motivation, which comes in the form of trust in and assurance from the police of a truly collaborative, long-standing effort. It is more than apparent, based on the findings, that the norms and narratives that exist in any community play a commanding role in the behavior of the individuals who comprise it, but are not devoid of the ability of transformation.

To overcome the negative norms and narratives that exist within particular communities, discussions need to take place between differing groups of community members. However, according to Kennedy (2009), discussions of this type very rarely occur between community groups. "These strong beliefs therefore go unexamined, unchallenged, and become even more deeply internalized. The result is a profound racial schism with impact and implications well beyond issues of crime and drugs” (Kennedy 2009:144). Therefore, the previous narratives illustrate the importance of mutually engaging law-enforcement officials and community members to become acquainted with the positions of each in an effort to broaden each party's understanding of the other and to reach a degree of mutual understanding and perspective.

\section{Knowledge and Awareness}

An additional key aspect of the overt drug elimination strategy is the significance of obtaining and maintaining the support of community residents throughout the entire implementation of the strategy. One element that emerged during the community resident focus group was the level of knowledge and awareness the community residents have as it relates to the strategy and to the neighborhood in general. The residents were asked what their knowledge and perceptions were of the overall strategy in terms of what was explained to them about their strategy, why their neighborhood was chosen, and what actually occurred from their perspective. Although varied awareness levels about the overall strategy were present among the participants, every participant was aware of the sting operation that took place several months before. Even though 
several exaggerated descriptions of what occurred during the sting were presented, most of the descriptions were pretty accurate, especially in terms of how many arrests took place. In addition, of the community residents who were familiar with the notification sessions, their perceptions of why they occurred and what they entailed were accurate.

Not only were the residents aware of the overall overt drug elimination strategy but they also had a very strong knowledge of general occurrences in the neighborhood. For instance, the focus group participants were exceptionally knowledgeable about the temporal patterns of the drug dealers in the area. According to the participants, the open-air drug dealers work in shifts. After five o'clock in the evening until the morning is the busiest time. Overt dealing is also very busy around citywide pay days. The residents also were aware of locations throughout the community where the dealers hide from law-enforcement officials who are patrolling the area.

The previously cited narratives illustrate that the community residents in this particular neighborhood, overall, understood the general principles behind the strategy. In addition, the residents possessed an enormous depth of understanding and knowledge about the community of which they are a part. The aforesaid findings illustrate that it is possible for law-enforcement officials to educate the community about the strategy and to build understanding of the overall model despite possible normative misunderstandings that exist between the various sectors of the community. Moreover, the community residents know a great deal about what goes on within their particular neighborhood. Therefore, it can be very useful for law-enforcement officials to engage the residents to obtain pertinent information that may otherwise go unknown to the police.

\section{Youth Support and Engagement}

Drug markets that operate in public spaces are toxic to neighborhoods (Weisburd and Mazerolle 2000; Wilson and Kelling 1982). The overt drug elimination strategy asserts that one of the toxic elements open-air drug dealing brings to communities is that the illegitimate activities attract area youth and children into the drug trade (Frabutt et al. 2006). Moreover, the drug trade creates norms and ideas among youth in support of drug dealing and in opposition to school and employment (Kennedy 2009). One concern voiced by the study's participants was for the youth in the community who observe and are influenced by the illegal behaviors that occur within the neighborhood. The participants also noted that some youth know more about the drug dealers in the area than the police. The community residents agreed that more activities need to be planned for young children to engage in, particularly after school and during the summer, so the amount of time they spend in the presence of illegitimate activities can be decreased. Moreover, the participants noted the need for increased parental involvement to keep young children away from the illegitimate activities that may be taking place.

The statements expressed by the focus group participants regarding children in the neighborhood show the need to deter drug and criminal activity, indicating that such markets negatively affect 
the children in the communities where overt drug dealing occurs. As stated previously, open-air drug markets create negative norms among neighborhood youth (Harcopos and Hough 2005) that, according to Frabutt et al. (2006), consist of ideas that imprisonment increases street status, and that it is not masculine to succeed in educational endeavors or to work beginning-level jobs (see also Kennedy 2009). The negative attitudes that are created because of open-air drug markets are the very positions that guide youth toward the drug trade in the first place. Therefore, if overt dealing could be deterred, then greater opportunities would arise to restore the existing negative narratives into more positive ones, encouraging a legitimate work ethic, the importance of education, and the notion that jail or prison will only hinder one's overall life chances.

\section{Strategy Maintenance and Police Visibility}

Based on the overt drug elimination strategy, the follow-up or maintenance period is directed by community partners and law-enforcement officials collectively. According to Frabutt and colleagues, this strategy "allows limited resources to be used most strategically through policecommunity partnerships to reduce drug dealing and improve community safety and community quality" (2006:25-26). During the maintenance phase of the strategy, the community follows up with the notified offenders by making contact with them immediately after the call-in or notification session to see whether they are receiving the assistance they need to discontinue dealing drugs. In addition, law-enforcement officials attend meetings that take place in the neighborhood in which the strategy was implemented and notify the community residents of arrests, convictions, and success stories of the notified offenders (Fealy, Sumner, and Kennedy 2006). Even though the strategy calls for a collective maintenance phase by the community and law-enforcement partners, the focus group participants placed particular emphasis on the need for police visibility in deterring criminal and drug behavior in their neighborhood.

The focus group participants attributed at least part of the reduced drug dealing to increased police visibility and inspection. One major suggestion made by many of the community residents was that the police should continue to increase their visibility throughout the community. A great deal of emphasis was placed on the foot patrol that was previously stationed within the neighborhood and it was expressed by the residents that the community was much safer when this patrol was in place. In addition, it was noted that the residents would like the officers to get out of their patrol cars to maximize surveillance, due to the fact that a good deal of crime occurs hidden from the view of officers in their patrol cars, such as behind buildings or bushes.

\section{Impact of the Strategy}

The main impacts of the overt drug elimination strategy are the removal of open-air drug markets and a decrease in the types of violent crime associated with these markets. According to the focus group participants, the positive impacts of the strategy in this neighborhood were illustrated by various aspects that included, but were not necessarily limited to, decreases in overt drug dealing, violent crime, and quality-of-life crime; increases in feelings of personal safety and 
a sense of community; and the establishment of trust between the community residents and lawenforcement officials.

Overall, the focus group participants felt much safer in the community after the strategy than before. Individuals in the community were no longer afraid to walk around in the area, because they felt confident that the police were protecting them. In addition, various individuals within the community are creating positive events and activities for the local youth and other community members to engage in. However, the feeling of safety that many of the residents felt was relatively short lived and started to lessen a few months after the initial notification occurred. In addition, the community residents expressed that although overt drug dealing was still present in the area, it has decreased significantly since the implementation of the strategy particularly during daytime hours.

The participants also indicated that, after the strategy, community members were more willing to report criminal and illegitimate behaviors to the police, which helped to decrease the overt dealing and subsequent violent crime that was occurring in the area. The increased enthusiasm to inform law-enforcement officials of negative behaviors that continued to occur after the implementation of the strategy was most certainly a product of an increased level of trust of the community residents in the police. The fact that the residents were more willing to contact lawenforcement officials after the implementation of the strategy illustrates that long-standing divisions between law enforcement and the community can be broken down and mended through the implementation of this strategy.

\section{Limitations}

Several limitations to this research study exist. First, the focus group participants were asked to retrospectively recall information pertaining to the strategy relatively long after its implementation. Thus, the possibility exists that the participants' responses may have been shaped by their current experiences within their communities and with law-enforcement officials. However, as with many criminal justice interventions, the focused deterrence strategy is a process that involves many phases (e.g., ongoing collaboration among social actors, community support, and efforts by law enforcement to identify and react to individuals who engage in criminal behaviors) making the identification of a definitive finishing point difficult to determine. Thus, for the present study, having a time lag between the portion of the intervention when the most social actors are actively engaged and the hosting of the focus groups is important to adequately assess community members' perceptions of the impact of the full strategy. However, future scholarship examining the pulling levers model would be strengthened by using a pre- and posttest intervention design and incorporating a component analysis to extricate the specific phases of the strategic process that are most salient for community residents.

Second, the number of participants in one of the focus groups was relatively small (three participants). Based on the difficulties in recruiting community residents for participation and the 
depth of the information obtained, the data were included in the study. The data obtained from the smaller focus group occurred in the same city as the focus group with eight participants. Thus, the information from the focus groups collectively can be used to corroborate and/or disconfirm the views of the smaller group. However, future examinations would benefit from including focus groups that are all relatively the same size.

Despite the limitations, the current investigation helps illustrate the importance of community engagement and the imperative role the community plays in this overt drug elimination strategy. Not only can the community residents aid in deterring potential future criminal behavior but they can also inform institutional stakeholders of incidents that occur in the area through the acquisition of direct, firsthand knowledge.

\section{Appendix A}

\section{City Characteristics}

The strategy implementation occurred in two urban centers of North Carolina. Using Census 2000 data, the following information is provided to describe the demographic characteristics of the intervention sites (Frabutt, Shelton, et al. 2009).

City Characteristics for Each Implementation Site

\begin{tabular}{|l|l|l|l|}
\hline & $\begin{array}{l}\text { City 1, Community A } \\
(n=11)\end{array}$ & $\begin{array}{l}\text { City 1, Community B } \\
(n=3)\end{array}$ & $\begin{array}{l}\text { City 2, Community C } \\
(n=8)\end{array}$ \\
\hline $\begin{array}{l}\text { Size of area (in } \\
\text { acres) }\end{array}$ & 815 & 838 & 159 \\
\hline \% white population & $46 \%$ & - & $2 \%$ \\
\hline \% black population & $32 \%$ & $91 \%$ & $94 \%$ \\
\hline $\begin{array}{l}\text { \% Hispanic } \\
\text { population }\end{array}$ & $23 \%$ & - & $3 \%$ \\
\hline $\begin{array}{l}\text { Median household } \\
\text { income }\end{array}$ & $\$ 22,690-\$ 36,670$ & $\$ 10,620-\$ 22,680$ & $\$ 13,330-\$ 16,519$ \\
\hline $\begin{array}{l}\text { Median per capita } \\
\text { income }\end{array}$ & $\$ 12,605$ & - & $\$ 7,227$ \\
\hline \% homeowners & $26 \%$ & $20 \%$ & $13 \%$ \\
\hline \% rental homes & - & $70 \%$ & $76 \%$ \\
\hline$\%$ vacant homes & - & $10 \%$ & $11 \%$ \\
\hline
\end{tabular}

\section{Appendix B}

Community Member Focus Group

Discussion Guide 
Good morning. Thank you for being here. I'm [name]. I [insert occupation] and I'm part of the research team that invited you to be here this morning. We're here to talk about what the police and others have done in this neighborhood to try to stop people from selling illegal drugs.

\{Introduce other team members and tell where they work.\}

Before we start, I want to be sure you understand what we're going to do and that you definitely want to participate. We have a long form. We need you to read and then sign if you do want to take part in this group. I'll go through the form with you; please ask me questions if there's anything in the form you don't understand.

\{Review Informed Consent Form, answer any questions, and collect signed forms; allow anyone who prefers not to sign to leave before proceeding.\}

\{Distribute gift cards.\}

\{Turn on tape recording.\}

This research is part of a larger study funded by the National Institute of Justice. I'm going to be asking you some questions, and I want you to know that there are no right or wrong answers. We do not work for the police department, the housing authority, or any community group, so we are not hoping you will answer the questions in any particular way. We just want each of you to tell us what you've seen and what you think and feel about it, so we can provide an honest and accurate report to the National Institute of Justice.

Now, there are some rules I need you to follow during this discussion:

- I'd like to refer to you by your first names and for you to call me Lynn, if that is OK with you. To be sure, I remember your name, please write the name you'd like me to call you on the "name tent." If you do not want your real first name to be on the tape recording, just make up a name you want to use. As it says on the form you signed, we will not be telling anyone else who said what during this discussion.

- For us to be able to hear what each of you has to say, only one person can talk at a time.

- It's my job to get us through the whole list of questions and to give everyone a chance to talk, so sometimes I may have to ask you to stop so we can hear from someone else or so we can move on to another question. Each person may not get to answer every question — and some questions you may not want to answer-but I want to be sure all of you have a good chance to tell us what you're thinking.

- Remember, from our point of view, there are no right or wrong answers.

OK, let's get started. We're talking about the specific project called [specific to each initiative area]. For this project, the police did a lot of surveillance of drug dealing in the neighborhood and some undercover work to build cases against the dealers. [Provided additional information 
specific to each initiative area.] The questions I'm going to ask you are about that notification, or about things that happened before it or after it. You may or may not remember some things, but that's OK.

1. What do you think of your community in terms of criminal activity?

2. What do you think of your community in terms of personal safety?

3. What are your perceptions of the police?

4. What is the greatest concern in this community?

5. Have you heard about the recent efforts by the police department to reduce street drug sales in your neighborhood?

If yes continue below, if no move to Question 2.

a. How did you hear about these efforts?

b. When did you hear about these efforts?

c. As a community member, are you working with the police department to keep the community free from street-level drug dealing? If yes, how?

d. Did anyone explain to you why your community had been selected for this initiative?

e. Were you aware of the notification in your community in 2005?

If yes continue below, if no move to Question 2.

f. Did you attend the notification in your community?

g. What is your understanding of how the notification process works?

h. Were you involved in the notification? If so, how?

i. What did you think of your community, in terms of criminal activity, before the notification?

j. What did you think of your community, in terms of criminal activity, after the notification?

$k$. What did you think of your community, in terms of personal safety, before the notification?

1. What did you think of your community, in terms of personal safety, after the notification?

$\mathrm{m}$. What were your perceptions of the police before the notification?

$\mathrm{n}$. What were your perceptions of the police after the notification?

o. Have you seen any changes in your community since the notification?

a. If so, what changes have you seen?

p. What was the greatest concern to this community before the notification?

q. What has been the greatest concern to this community after the notification? 
That's all the questions I have. Thank you so much for talking with us this morning. You have been very helpful.

\section{Authors' Note}

The opinions, findings, and conclusions or recommendations expressed in this article are those of the authors and do not necessarily reflect the views of the Department of Justice.

\section{Declaration of Conflicting Interests}

The author(s) declared no potential conflicts of interest with respect to the research, authorship, and/or publication of this article.

\section{Funding}

The author(s) disclosed receipt of the following financial support for the research, authorship, and/or publication of this article: This research was supported by the National Institute of Justice (Award No. 2006-IJ-CX-0034).

\section{Notes}

1. References to the specific cities, neighborhoods, and individuals are not used to ensure confidentiality.

2. See Appendix A for a table of city characteristics for each intervention site.

\section{References}

Braga, Anthony A. 2008. "Pulling Levers Focused Deterrence Strategies and the Prevention of Gun Homicide.” Journal of Criminal Justice 36(4):332-43.

Braga, Anthony A., Glenn L. Pierce, Jack McDevitt, Brenda J. Bond, and Shea Cronin. 2008. “The Strategic Prevention of Gun Violence among Gang-Involved Offenders.” Justice Quarterly 25(1):132-62.

Curtis, Ric and Travis Wendel. 2007. “'You're Always Training the Dog': Strategic Interventions to Reconfigure Drug Markets.” Journal of Drug Issues 37(4):867-92.

Fealy, Jim M., Marty Sumner, and David M. Kennedy. 2006. Eliminating Overt Drug Markets in High Point, North Carolina. Application submitted for the Herman Goldstein Award, Community-Oriented Policing Services, U.S. Department of Justice. Retrieved September 26, 2012 http://www.popcenter.org/library/awards/goldstein/2006/06-20\%28F\%29.pdf. 
Frabutt, James M., M. Kristen Hefner, Kristen L. Di Luca, Terri L. Shelton, and Lynn K. Harvey. 2010. “A Street Drug Elimination Initiative: The Law Enforcement Perspective.” Policing: An International Journal of Police Strategies \& Management 33(3):452-72.

Frabutt, James M., M. Kristen Hefner, Lynn K. Harvey, Kristen L. Di Luca, and Terri L. Shelton. 2009. "Key Community Stakeholders in a Police-Community Partnership to Eliminate Street-Drug Markets: Roles, Engagement, and Assessment of the Strategy.” Crime, Punishment, and the Law: An International Journal 2(1-2):55-70.

Frabutt, James M., Terri L. Shelton, Kristen L. Di Luca, Lynn K. Harvey, and Mary K. Hefner. 2009. A Collaborative Approach to Eliminating Street Drug Markets through Focused Deterrence. Final Report to the United States Department of Justice, Office of Justice Programs, National Institute of Justice (Grant \#2006-IJ-CX-0034). Greensboro: Center for Youth, Family, and Community Partnerships, The University of North Carolina at Greensboro.

Frabutt, James M., David A. Kennedy, K. Davis Gooding, Lynn K. Harvey, and Mike Carmichael. 2006. A Collaborative Approach to Eliminating Street Drug Markets through Focused Deterrence. Grant proposal submitted to the National Institute of Justice.

Harcopos, Alex and Mike Hough. 2005. Drug Dealing in Open-Air Markets. Problem-Oriented Guides for Police, Problem-Specific Guides Series (No. 31). Washington, DC: U.S. Department of Justice, Office of Community Oriented Policing Services. Hough, Mike and Mark Edmunds. 1999. “Tackling Drug Markets: An Eclectic Approach.” Studies on Crime and Crime Prevention 8(1):107-31.

Kennedy, David M. 1998. "Pulling Levers: Getting Deterrence Right.” National Institute of Justice Journal (July) 236:2-8.

Kennedy, David M. 2009. Deterrence and Crime Prevention: Reconsidering the Prospect of Sanction. London: Routledge.

Knutsson, Johannes. 1997. "Restoring Public Order in a City Park.” Pp. 133-52 in Policing for Prevention: Reducing Crime, Public Intoxication and Injury. Crime Prevention Studies. Vol. 7., edited by R. Homel Monsey. New York: Criminal Justice Press.

Weisburd, David and Lorraine G. Mazerolle. 2000. "Crime and Disorder in Drug Hotspots: Implications for Theory and Practice in Policing.” Police Quarterly 3(3):331-49.

Weiss, Robert S. 1994. Learning from Strangers: The Art and Method of Qualitative Interview Studies. New York: The Free Press.

Wilson, James Q. and George Kelling. 1982. Broken windows. The Atlantic Monthly 249:29-38.

Bios 
M. Kristen Hefner is currently a doctoral student at the University of Delaware. She received a B.A. in Psychology and a minor in criminology from North Carolina State University in 2003 and an M.A. in Sociology with a concentration in criminology from the University of North Carolina at Greensboro. Her primary research interests focus on gender, prisons as social institutions, and law \& society.

James M. Frabutt, Ph.D., is a faculty member in the Mary Ann Remick Leadership Program in the Alliance for Catholic Education and Concurrent Associate Professor of Psychology at the University of Notre Dame. He previously served as Deputy Director of the Center for Youth, Family, and Community Partnerships at the University of North Carolina at Greensboro. He has employed action-oriented, community-based research approaches to areas such as juvenile delinquency prevention, school-based mental health, teacher/administrator inquiry, racial disparities in the juvenile justice system, and community violence reduction.

Lynn K. Harvey, Ph.D., is Associate Professor of Sociology in the Department of Behavioral Sciences and Social Work at Winston-Salem State University (WSSU) in Winston-Salem, North Carolina. He was affiliated with WSSU's Center for Community Safety from its opening in January 2001 until 2009, and he led the university’s new Justice Studies program through its first two years. Through the Center Dr. Harvey's work focused on domestic violence research and, often in collaboration with researchers from other universities, the evaluation of numerous community-based initiatives aimed at reducing violence and illicit drug markets. He continues to address community safety issues through research on intimate partner violence.

Kristen L. Di Luca, is a Program Specialist for the Center for Youth, Family, and Community Partnerships at the University of North Carolina at Greensboro. She earned her Master of Arts degree in Sociology with a Criminology concentration from UNC Greensboro and her Bachelor of Arts degree in Psychology from Humboldt State University. Her expertise bridges community and media engagement as well as research primarily working with nine Project Safe Neighborhoods sites and 27 law enforcement partner agencies in the Middle District.

Dr. Terri L. Shelton is the Vice Chancellor for Research and Economic Development and is the Carol Jenkins Mattocks Distinguished Professor in Psychology at the University of North Carolina at Greensboro, overseeing the University’s \$46 million in sponsored research. She received her Ph.D. in Clinical Psychology with a minor in Child and Family Studies and a clinical internship in Pediatrics and is a licensed psychologist and health service provider in the state of NC. She has over 25 years of experience in clinical intervention, teaching and technical assistance, workforce development, and large scale community-based participatory outcome research working with children, families, and communities at-risk. Prior to her appointment as Vice Chancellor, she oversaw the work of the Center for Youth, Family, and Community Partnerships including over \$20 million in federal, state, local, and foundation grants and contracts ensuring the health and well-being of youth, families, and communities by engaging partnerships that bridge research, policy, and practice. 